\title{
Strategies to reduce alcohol-related harms and costs in Canada: A comparison of provincial policies
}

Norman Giesbrecht ${ }^{1,2}$, Ashley Wettlaufer ${ }^{1}$, Stephanie Simpson ${ }^{3}$, Nicole April ${ }^{4}$, Mark Asbridge ${ }^{5}$, Samantha Cukier ${ }^{6}$, Robert E. Mann ${ }^{1,2}$, Janet McAllister ${ }^{7}$, Andrew Murie ${ }^{8}$, Chris Pauley ${ }^{9}$, Laurie Plamondon ${ }^{4}$, Timothy Stockwell ${ }^{9}$, Gerald Thomas $^{10}$, Kara Thompson $^{9}$, and Kate Vallance ${ }^{9}$

${ }^{1}$ Centre for Addiction \& Mental Health, Social \& Epidemiological Research Dept., Toronto, Ontario, Canada

${ }^{2}$ Dalla Lana School of Public Health, University of Toronto, Toronto, Ontario, Canada

${ }^{3}$ University of Western Ontario, London, Ontario, Canada

${ }^{4}$ Institut national de santé publique du Québec, Québec City, Québec, Canada

${ }^{5}$ Dalhousie University, Departments of Community Health and Epidemiology, and Emergency Medicine, Halifax, Nova Scotia, Canada

${ }^{6}$ Johns Hopkins Bloomberg School of Public Health, Center on Alcohol Marketing \& Youth, Baltimore, United States

${ }^{7}$ Centre for Addiction and Mental Health, Health Promotion and Prevention, London, Ontario, Canada

${ }^{8}$ Mothers Against Drunk Driving (MADD) Canada, Oakville, Ontario, Canada

${ }^{9}$ Centre for Addictions Research of BC, University of Victoria, Victoria, British Columbia, Canada

${ }^{10}$ Okanagan Research, Summerland, British Columbia, Canada

\section{Abstract}

Aims: To compare Canadian provinces across 10 research-based alcohol policy and program dimensions.

Design and Measures: The 10 Canadian provinces were assessed on the following 10 policy dimensions: alcohol pricing; alcohol control system; physical availability; drinking and driving; marketing and advertising; legal drinking age; screening, brief intervention, and referrals; server training, challenge, and refusal programs; provincial alcohol strategy; warning labels and signs. Data were collected from official documents, including provincial legislation, regulations, and policy, and strategy documents. Three international experts on alcohol policy contributed to refining the protocol. Provincial scores were independently determined by two team members along a 10-point scale for each dimension, and the scores were expressed as a percentage of the ideal. Weighting of dimensions according to scope of impact and effectiveness was applied to obtain the final scores. National and provincial scores were calculated for each dimension and consolidated into overall averages.

Findings: Overall, the consolidated national mean is $47.2 \%$ of the ideal, with Ontario scoring highest at 55.9\%, and Québec lowest at 36.2\%. Across dimensions, Legal Drinking Age and Challenge and Refusal Programs scored highest at 75\% and 61\%, respectively, while Warning Labels and Signs scored lowest at $18 \%$ of the ideal. Pricing, rated third highest among dimensions at $57 \%$, should nevertheless remain a priority for improvement, given it is weighted highest in terms of effectiveness and scope.

Conclusions and Implications: Policy dimension scores vary among the provinces, with substantial room for improvement in all. Since spring 2013, several provinces have taken steps to implement specific alcohol policies. Concerted action involving multiple stakeholders and alcohol policies is required to reduce the burden of alcohol problems across Canada.

\section{Introduction}

\section{Background \& Rationale}

This study provides a province-by-province review of current policy and program measures known to reduce alcohol-related harm and compares results among Canadian jurisdictions in relation to the ideal. The results are presented as comparative score cards, consistent with a well-established approach that not only makes strengths and weaknesses explicit but also sets the stage for positive change through the adoption of effective health-oriented policies and programs. The score card approach has been utilized in various contexts (Anderson, Chisholm, \& Fuhr, 2009; Babor et al., 2010; Brand, Saisana, Ryan, Pennoni, \& Lowenfels, 2007; Karlsson \& Österberg, 2001; Lin \&

Correspondence: Norman Giesbrecht, PhD, Centre for Addiction \& Mental Health, 33 Russell St. Toronto, Ontario, Canada M5S 2S1. Telephone: 416-535-8501 x36895; Fax: 416-595-6899; Email: norman.giesbrecht@camh.ca

Financial support: The authors acknowledge funding from the Canadian Institutes of Health Research in support of the project "Reducing Alcohol-Related Problems by Implementing Evidence-based Tools that Translate Research Knowledge into Prevention Practice,” FRN \#114100 (Principal Investigator: Norman Giesbrecht). The in-kind support provided by our co-investigators' organizations is gratefully acknowledged. Mark Asbridge is supported in part by a Canadian Institutes of Health Research New Investigator Award.

Declaration of interest: The authors have no conflict of interest to declare.

Keywords: alcohol policies, interprovincial comparison, Canada, knowledge transfer 
Durbin, 2008). Mothers Against Drunk Driving (MADD) Canada has ranked Canadian provinces on drinking and driving counter-measures (Solomon, Cardy, Noble, \& Wulkan, 2012). In the first six years following the first two MADD Canada report cards there were more than 65 legislative changes across Canada (A. Murie, personal communication, January 23, 2013). Brand et al.'s (2007) comparative analysis of alcohol control policies across 30 countries found that strong alcohol control policy implementation was associated with reduced per capita consumption. A recent U.S.-based project (Naimi et al., 2014; Nelson et al., 2013) used a ranking approach that confirmed the main finding by Brand et al. (2007), and Carragher, Byrnes, Doran, and Shakeshaft (2014) assessed the adequacy of 16 national alcohol policies in nine areas in the Western Pacific.

This study addresses a well-recognized problem whereby research findings, including those involving alcohol, often fail to become translated into practice. Characterized as the "Valleys of Death," such failure represents "deficiencies in the development and dissemination of guidelines and their adoption into practices, despite their proven value" (Strategies for Patient-Oriented Research, 2011). Therefore, one of the aims of this study is to translate research findings into practical guidelines that can be disseminated and used in practice-based and policy implementation settings. To this end, the ultimate target audience includes a broad range of stakeholders, including various levels of government, involved in the development of alcohol policy and program initiatives in each province.

\section{Alcohol Consumption and Harm}

High-risk drinking practices are responsible for the considerable burden of alcohol-related harm in Canada (Canadian Public Health Association, 2011; Giesbrecht, Stockwell, Kendall, Strang, \& Thomas, 2011). In 2010, the Canadian Centre on Substance Abuse (CCSA) introduced a set of guidelines defining at-risk drinking in terms of consumption levels. The National Low-Risk Drinking Guidelines (LRDG) recommend consuming no more than two standard drinks per day and 10 per week for women, and three standard drinks per day and 15 per week for men; and for special occasions consuming no more than three standard drinks for women, and four standard drinks for men. A "standard drink" is equal to a 341-ml (12-oz.) bottle of $5 \%$ strength beer, cider, or cooler; a 142-ml (5oz.) glass of $12 \%$ strength wine; or a $43-\mathrm{ml}$ (1.5-oz.) shot of $40 \%$ strength spirits. A Canadian standard drink is defined as $17.05 \mathrm{ml}$ or $13.45 \mathrm{~g}$ of ethanol (Butt, Beirness, Gliksman, Paradis, \& Stockwell, 2011).

In 2010, an estimated 20\% of Canadian adults exceeded the upper (occasional) daily limit of the LRDG at least once per month (Statistics Canada, 2011a). Furthermore, it is estimated that more than $70 \%$ of all alcohol consumed is by the $20 \%$ who drink the most (Stockwell, Zhao \& Thomas, 2009). If one uses the lower threshold criteria of any instance of exceeding the upper daily (occasional) limit of the LRDG in the past year, the percentage of current drinkers classified as risky is $41 \%$ of females aged 15 and older and $49 \%$ of males aged 15 and older. Based on this measure, about $45 \%$ of the population aged 15 and older would be considered risky drinkers (Statistics Canada, 2011a; b).

In 2002, at-risk drinking was responsible for $8 \%$ of all deaths for those under the age of 70 , and $7 \%$ of all hospital days in Canada (Patra, Taylor, Rehm, Baliunas, \& Popova, 2007). Furthermore, a 33\% incident rate of second-hand effects of drinking - that is, harm to others from alcoholwas reported in 2005 for the previous year (Giesbrecht, Cukier, \& Steeves, 2010; Kellner, 2005). Overall, there was a 13\% increase in per-adult consumption between 1996 and 2010 (Statistics Canada, 2011b). Countrywide, the financial burden in relation to healthcare, law enforcement, and lost productivity is approximately $\$ 14.6$ billion annually (Rehm et al., 2006), and in more than half the provinces, direct alcohol-related costs to governments exceed the direct revenue (Thomas, 2012). It is estimated that the wide adoption of the CCSA low-risk guidelines would result in an annual reduction of 4,600 alcohol-related deaths (Butt et al., 2011).

An extensive body of research has identified a range of policy and program measures to reduce the prevalence of risky drinking practices and the attendant harm (e.g., Anderson et al., 2009; Babor et al., 2010: WHO, 2010). Such measures introduce little impact to low-risk drinkers and they are not intended as a prohibitionist approach; rather, they involve a health promotion perspective aimed at building public policy with the goal of making the healthier choice the easier choice for people (World Health Organization, 1986).

\section{Methods}

\section{Selection of the Policy Dimensions}

Most substantive policy and program options for addressing alcohol-related harm lie within the domain of provincial governments, and, accordingly, these options were selected as the principal focus for the study. The project team conducted a review of the scientific literature that identified effective alcohol policy dimensions. In particular, we examined the reviews and analyses by Anderson et al. (2009), Babor et al. (2010), Brand et al. (2007), and Karlsson and Österberg (2001), as well as the recommendations of the National Alcohol Strategy (2007), the Canadian Public Health Association position paper on alcohol (2011), and the dimensions of the World Health Organization (WHO) Global Strategy to Reduce the Harmful use of Alcohol (2010). Table 1 indicates substantial convergence among the policy dimensions that we focused on and the dimensions used in six analyses published between 2001 and 2010. Further information is provided in Appendix A. Initially 17 modules were considered, but some were combined, and others were judged not to be alcohol policies but rather measures of impacts of alcohol-related risk or harm. 
Table 1

Overview of alcohol policy dimensions considered in seven analyses, 2006-2013

\begin{tabular}{|c|c|c|c|c|c|c|c|}
\hline Dimensions & $\begin{array}{c}\text { World Health } \\
\text { Organization, } \\
2010\end{array}$ & $\begin{array}{c}\text { Karlsson } \\
\& \\
\text { Österberg, } \\
2001\end{array}$ & $\begin{array}{c}\text { National } \\
\text { Alcohol } \\
\text { Strategy, } \\
2007\end{array}$ & $\begin{array}{c}\text { Brand } \\
\text { et al., } \\
2007\end{array}$ & $\begin{array}{c}\text { Anderson } \\
\text { et al., } \\
2009\end{array}$ & $\begin{array}{c}\text { Babor } \\
\text { et al., } \\
2010\end{array}$ & $\begin{array}{l}\text { Giesbrecht } \\
\text { et al., } 2013\end{array}$ \\
\hline Leadership and commitment & $\checkmark$ & $\checkmark$ & & & & & $\checkmark$ \\
\hline Awareness/education & $\checkmark$ & $\checkmark$ & $\checkmark$ & $\checkmark$ & $\checkmark$ & $\checkmark$ & $\checkmark$ \\
\hline Health services’ response & $\checkmark$ & & $\checkmark$ & & $\checkmark$ & $\checkmark$ & $\checkmark$ \\
\hline Community action & $\checkmark$ & & $\checkmark$ & $\checkmark$ & $\checkmark$ & & \\
\hline Drink-driving policies and countermeasures & $\checkmark$ & $\checkmark$ & $\checkmark$ & $\checkmark$ & $\checkmark$ & $\checkmark$ & $\checkmark$ \\
\hline Availability of alcohol & $\checkmark$ & $\checkmark$ & $\checkmark$ & $\checkmark$ & $\checkmark$ & $\checkmark$ & $\checkmark$ \\
\hline $\begin{array}{l}\text { Alcohol control system (alcohol } \\
\text { monopolies) }\end{array}$ & $\checkmark$ & $\checkmark$ & $\checkmark$ & & $\checkmark$ & $\checkmark$ & $\checkmark$ \\
\hline Marketing of alcoholic beverages & $\checkmark$ & $\checkmark$ & $\checkmark$ & $\checkmark$ & $\checkmark$ & $\checkmark$ & $\checkmark$ \\
\hline Pricing policies & $\checkmark$ & & $\checkmark$ & $\checkmark$ & $\checkmark$ & $\checkmark$ & $\checkmark$ \\
\hline $\begin{array}{l}\text { Reducing negative consequences of } \\
\text { drinking \& alcohol intoxication }\end{array}$ & $\checkmark$ & & $\checkmark$ & $\checkmark$ & $\checkmark$ & $\checkmark$ & $\checkmark$ \\
\hline $\begin{array}{l}\text { Minimum legal drinking age and underage } \\
\text { access to alcohol }\end{array}$ & $\checkmark$ & $\checkmark$ & $\checkmark$ & $\checkmark$ & $\checkmark$ & $\checkmark$ & $\checkmark$ \\
\hline $\begin{array}{l}\text { Reducing the public health impact of illicit } \\
\text { and informally produced alcohol }\end{array}$ & $\checkmark$ & & $\checkmark$ & & $\checkmark$ & & \\
\hline Monitoring and surveillance & $\checkmark$ & & $\checkmark$ & & & & \\
\hline
\end{tabular}

From this assessment, we eventually identified 10 policy and program dimensions within provincial jurisdiction. The choice of 10 policy dimensions principally reflected areas with strong evidence for effectiveness and potential for population reach (Babor et al., 2010, pp. 239-257; Anderson et al., 2009, Table 2). However, we also included dimensions on the basis of being supportive of the other evidence-based policy areas by creating a favorable environment for implementing effective policies (e.g., Warning Labels and Signs, and Provincial Alcohol Strategy).

\section{Selection of Indicators}

The team developed a set of indicators by which each dimension could be assessed. Selection of indicator measures was informed by Babor et al.'s (2010) comprehensive review. The quality and breadth of evidence, the effectiveness of the policy, and the potential for population reach were the primary factors considered when selecting the indicator measures. The list of indicators was refined to avoid duplication and to reflect the data that are available across all provinces.

\section{Development of Scoring Scales}

Once the indicators were identified, scoring scales were developed for each indicator, with the number of points in alignment with its potential contribution to the reduction of harm as per the policy ratings by Babor et al. (2010). These indicator values were the basis on which the policies were scored against. This score was converted to a percentage to reflect the extent to which any province attained the ideal.

\section{Weighting System}

A weighting system was developed to reflect the variation in the overall potential for impact among dimensions. Each dimension was rated along 5-point scales for scope (or population reach) and effectiveness, with higher scores indicative of broader and/or more effective policies. The two scores were multiplied to yield a weighting factor (see Table 2). The team based the rating of effectiveness and scope of each policy on the policy assessment included in Babor et al., 2010.

\section{Scoring Rubric Peer Review Process}

The complete scoring rubric went through a review process in which three international experts with extensive experience in alcohol policy analysis commented on the choice and the weighting of the policy dimensions and the indicators used. Six additional indicator measures were added to the scoring rubric based on expert feedback. The weighting and scaling of indicator measures were finalized at in-person meetings in 2011 and 2012, prior to data collection.

\section{Data Collection and Validation}

The status of specific policy indicators was assessed at the time of data collection (January 1-October 31, 2012). As such, only policies in place at the time of data collection 
Table 2

Alcohol policy dimensions, indicators and weightings

\begin{tabular}{|c|c|c|c|c|}
\hline Policy Dimension & Indicators & $\begin{array}{l}\text { Effectiveness } \\
\text { (out of 5) }\end{array}$ & $\begin{array}{c}\text { Scope } \\
\text { (out of 5) }\end{array}$ & $\begin{array}{c}\text { Total } \\
\text { Product }\end{array}$ \\
\hline 1. Pricing & $\begin{array}{l}\text { - Minimum prices } \\
\text { - Indexing prices to inflation } \\
\text { - Pricing on alcohol content }\end{array}$ & 4 & 5 & 20 \\
\hline 2. Control System & $\begin{array}{l}\text { - Type of retail system } \\
\text { - Alcohol sales beyond on- and off-premises retail outlets } \\
\text { - Emphasis on social responsibility } \\
\text { - Ministry responsible for oversight }\end{array}$ & 3 & 5 & 15 \\
\hline 3. Physical Availability & $\begin{array}{l}\text { - Regulations for outlet density } \\
\text { - Actual density } \\
\text { - Hours of operation }\end{array}$ & 3 & 5 & 15 \\
\hline 4. Drinking \& Driving & $\begin{array}{l}\text { - Licensing } \\
\text { - Licensing suspension and revocations } \\
\text { - Vehicle and remedial programs }\end{array}$ & 4 & 3 & 12 \\
\hline $\begin{array}{l}\text { 5. Marketing \& } \\
\text { Advertising }\end{array}$ & $\begin{array}{l}\text { - Comprehensiveness of regulations } \\
\text { - Enforcement of regulations } \\
\text { - Focus of the liquor board's website } \\
\text { - Sponsorship }\end{array}$ & 2 & 5 & 10 \\
\hline 6. Legal Drinking Age & $\begin{array}{l}\text { - Minimum legal drinking age and supporting legislation } \\
\text { - Enforcement of the legal drinking age in on-and off- } \\
\text { premises outlets }\end{array}$ & 4 & 2 & 8 \\
\hline $\begin{array}{l}\text { 7. Screening, Brief } \\
\text { Intervention, and } \\
\text { Referral }\end{array}$ & $\begin{array}{l}\text { - Inclusion of screening, brief intervention, and referral in a } \\
\text { provincial strategy or action plan } \\
\text { - Practice guidelines and/or position paper } \\
\text { - Fee for service codes }\end{array}$ & 4 & 2 & 8 \\
\hline $\begin{array}{l}\text { 8. Server Training, } \\
\text { Challenge \& Refusal }\end{array}$ & $\begin{array}{l}\text { - Server and management training program policy status } \\
\text { - Quality of the server and management training program } \\
\text { - Program enforcement } \\
\text { - Challenge and refusal program policy status } \\
\text { - Quality of the challenge and refusal program } \\
\text { - Program enforcement }\end{array}$ & 2 & 3 & 6 \\
\hline 9. Provincial Strategy & $\begin{array}{l}\text { - An alcohol focused provincial health strategy } \\
\text { - Range of policy interventions }\end{array}$ & 1 & 5 & 5 \\
\hline $\begin{array}{l}\text { 10. Warning Labels \& } \\
\text { Signs }\end{array}$ & $\begin{array}{l}\text { - Provincial policy on warning labels } \\
\text { - Quality of warning label messages } \\
\text { - Provincial policy on warning signs } \\
\text { - Quality of warning sign message }\end{array}$ & 1 & 4 & 4 \\
\hline Total: & & & & 103 \\
\hline
\end{tabular}

were evaluated. For each of the 10 dimensions, data were collected from official documents, including provincial legislation, regulations, policy, and strategy documents. For each province, these documents were identified and scanned to identify regulations that pertain to any of the 10 policy dimensions included in this study. As these documents were scanned, data and sources were abstracted into an Excel spreadsheet. Once all available official sources were scanned, additional information was obtained from annual reports and media releases, supplemented with data from Statistics Canada and MADD Canada.
Remaining data deficits were addressed by consulting directly with provincial alcohol regulators and with provincial ministries responsible for alcohol retail, alcohol regulation, and health. The accuracy of the data was verified by representatives of these organizations from each province. In very rare instances where it was not possible to obtain data in relation to a particular policy or program measure, the data were coded to indicate that the relevant measure was not in effect for that province. The data collected represent policies in place as of November 2012. 


\section{Data Scoring}

The scoring process was tested by having two team members independently score each dimension, blinded to which province was being assessed. Discrepancies in scoring were handled through an iterative process that involved discussions among the raters and the principal investigator. In total, the testing and data verification process identified an additional 27 indicators to be added to the scoring rubric. These were subsequently obtained and added to the provincial data sets. For final scoring, two team members independently assessed the data using the revised protocols and updated data sets. Results were reviewed by a third team member. Where the scores from the two independent scorers did not correspond exactly, the scoring discrepancies were resolved through an iterative process that involved discussions among the raters and the principal investigator.

The final score for each dimension was calculated by multiplying the percentage of the ideal by the weighting factor. To illustrate, the province of Ontario scored eight out of a possible 10 points in relation to the dimension of Legal Drinking Age, which converted to an $80 \%$ percentage of the ideal score. This dimension was assigned a weighting factor of eight, so the final weighted score for Ontario was 6.40 ( $80 \%$ of 8 ) (Table 2). Provinces were then ranked according to their final overall cumulative policy scores.

\section{Results}

This assessment of Canadian provincial alcohol policies identified examples of excellence for each of the 10 policy domains. However, it is important to note that the results provided in Figure 1 and Table 3 highlight the significant variation in the implementation of each policy and therefore suggest that much unrealized potential remains for alcohol harm reduction across the provinces. The bar graph in Figure 1 provides a general overview of provincial ranking for total weighted scores in terms of a percentage of the ideal for the total of all dimensions. Further, the bar graph indicates the total national average across the 10 provinces. As indicated, the average across 10 provinces was below 50\%. Overall, Ontario and British Columbia received the highest scores, at $55.9 \%$ and $53.4 \%$, respectively, and Prince Edward Island and Québec the lowest scores, at $41.0 \%$ and $36.2 \%$, respectively.

\section{Figure 1}

\section{Total Weighted Scores by Province}

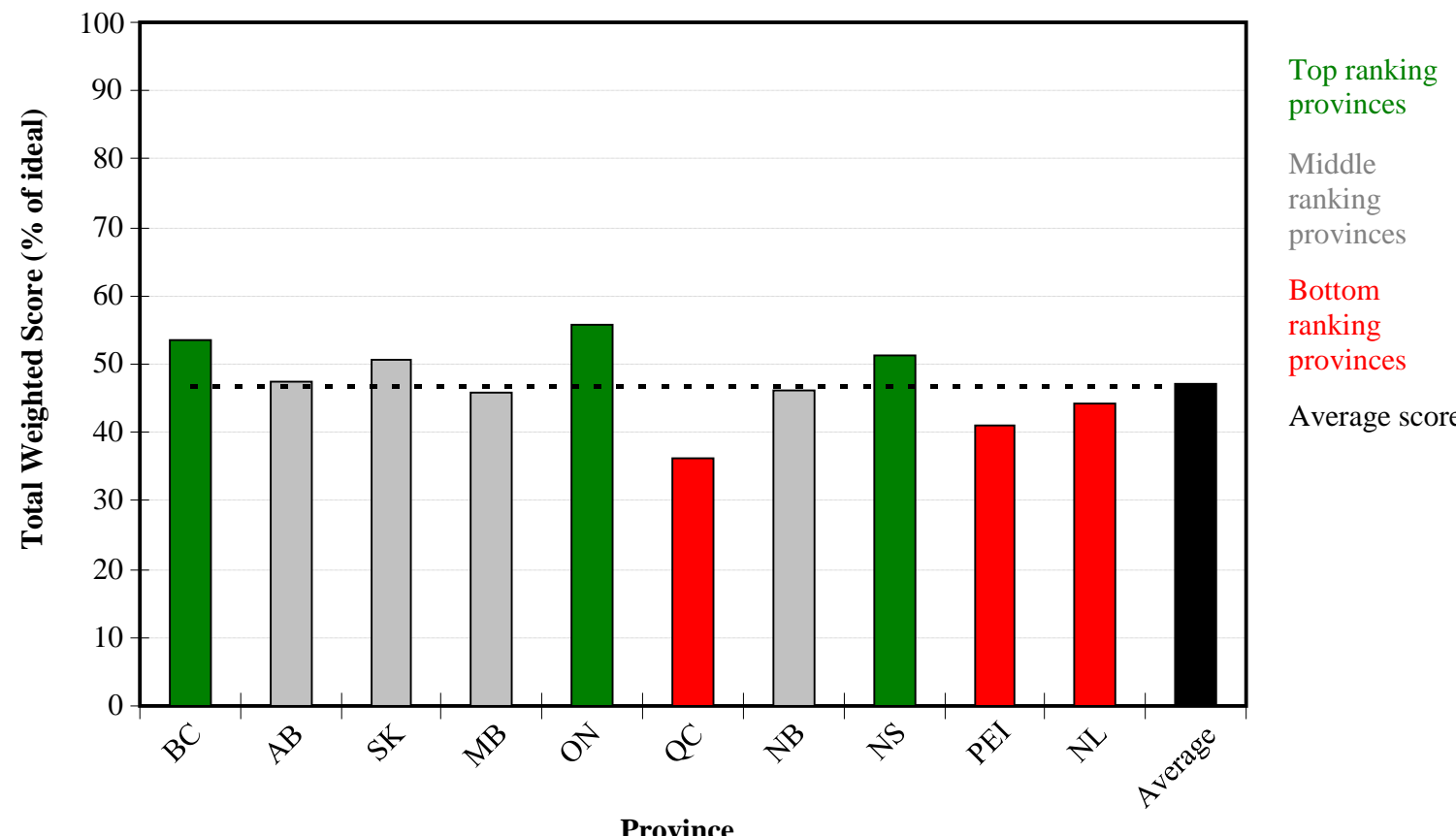

Legend: BC: British Columbia; AB: Alberta; SK: Saskatchewan; MB: Manitoba; ON: Ontario; QC: Québec; NB: New Brunswick; NS: Nova Scotia; PEI: Prince Edward Island; NL: Newfoundland and Labrador 


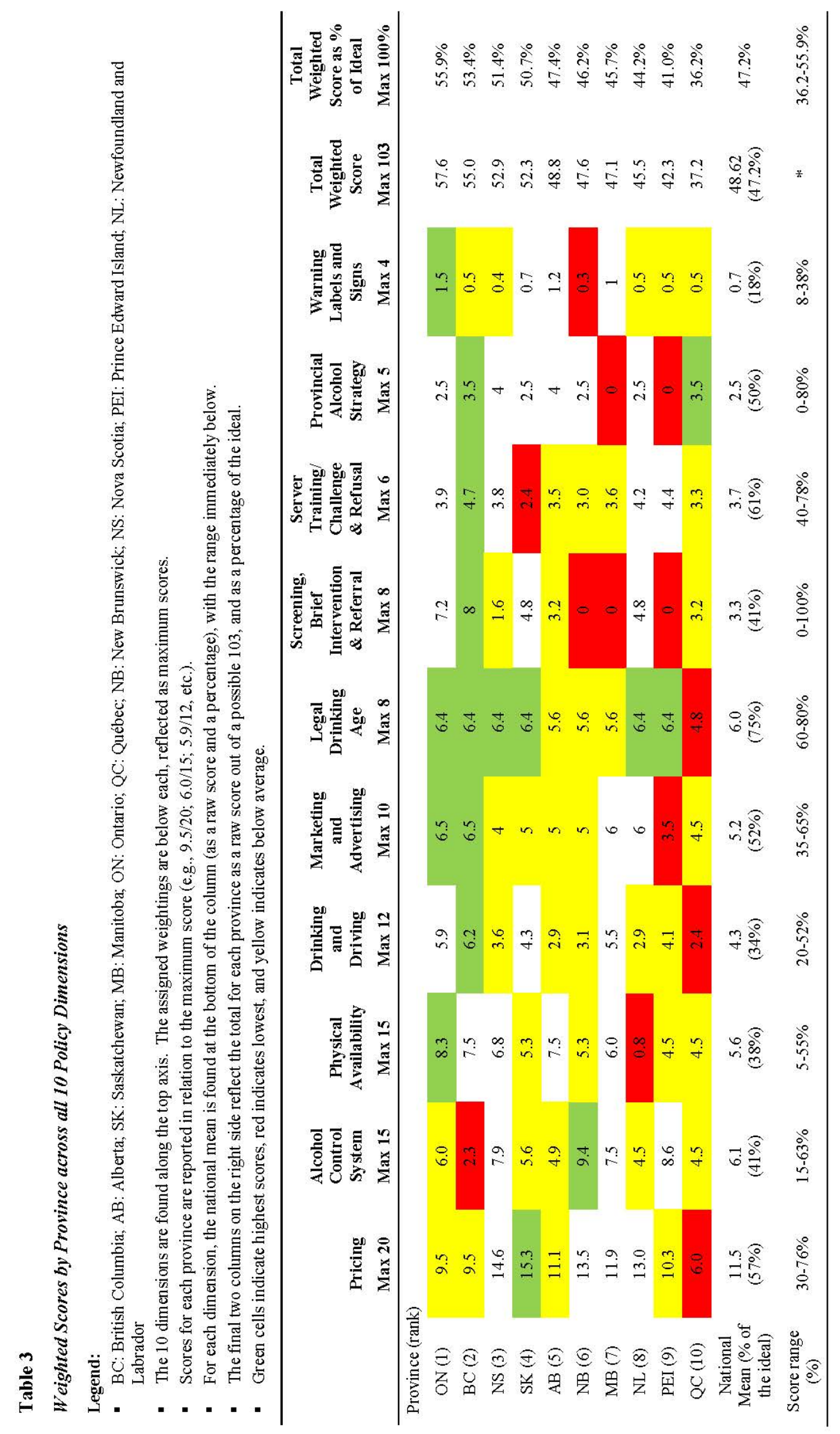


Table 3 provides a detailed look at provincial raw scores for the 10 policy dimensions. The dimensions are listed along the top axis, with the assigned weightings reflected as maximum scores below each dimension. For each dimension, the national mean is found at the bottom of the column (as both a raw score and a percentage), with the score range immediately below. The final two columns on the right side reflect the total for each province as a raw score out of a possible 103, and as a percentage of the ideal. Finally, green cells indicate highest scores, red indicates lowest, and yellow indicates mid-range scores.

The consolidated national mean is $47.2 \%$ of the ideal, leaving considerable unrealized potential for achieving public health and safety benefits through effective alcohol strategies. A notable nationwide strength was the implementation of policies pertaining to Legal Drinking Age and Server Training, Challenge, and Refusal, with national means of $75 \%$ and $61 \%$, respectively. The policy dimension most in need of improvement is Warning Labels and Signs, with the lowest national mean at $18 \%$ of the ideal, although the potential for unique impact is substantially less than other measures, such as Pricing, Type of Control System, and Controls on Density of Outlets. Further, although the national mean for Pricing is rated third highest among dimensions at $57 \%$, it should remain a priority for improvement given it is weighted highest overall in terms of scope and effectiveness.

\section{Discussion}

There was significant variation in the implementation of each policy, which suggests that much unrealized potential remains for alcohol harm reduction across the provinces. The average across 10 provinces was below 50\%, with few provinces scoring higher. The scores for Legal Drinking Age and Server Training, Challenge, and Refusal were above the inter-dimension average, while Warning Labels and Signs had the lowest score. Even the four dimensions considered to have the highest impact, based on effectiveness and scope/reach, did not have high averages: Pricing, 57\%, Alcohol Control System, 41\%, Physical Availability, 38\%, and Drinking and Driving CounterMeasures, 34\% (Table 3).

This study has some limitations. The study described general policy environments and did not focus on specific sectors or populations, such as First Nations or women. Nevertheless, based on earlier evidence and recommendations (Anderson et al., 2009; Babor et al., 2010; Brand et al., 2007, Canadian Public Health Association, 2011; World Health Organization, 2010), it is a reasonable assumption that these broad policies have substantial potential for impact across most, if not all, subsectors of the population. Some measures were not taken into consideration as indicators because the information was not centralized, or not available to the team. There are ongoing and sometimes very hasty changes in alcohol policy and politics; our analysis is based on data collected up to November 2012, and policies proposed or adopted since then are not reflected in the findings.

The study also has several strengths. The choice of 10 policy dimensions reflected areas with strong evidence for effectiveness. We also included dimensions on the basis of being supportive of other evidence-based policy areas by creating a favorable environment for implementing effective policies (e.g., warning labels). Our dimensions were based on both national (Canadian Public Health Association, 2011; Giesbrecht et al., 2011; National Alcohol Strategy, 2007) and international work on this topic (Anderson et al., 2009; Babor et al., 2010; World Health Organization, 2010). The weighting factors took into account evidence of effectiveness in scope of impact and reducing alcohol-related harm; for example, the dimension of price received 5 out of 5 on scope because nearly all drinkers are affected by price changes. The 10 dimensions and indicators and the weighting scheme were reviewed by three international experts before our data collection protocol was finalized. The scoring criteria were developed to be specific and measurable. The raw data were checked for accuracy by the appropriate government agencies prior to scoring. The application of scores was conducted independently by three team members, and discrepancies were resolved by key team members and the principal investigator.

The primary aim of this project was to assess the current state of alcohol control policies across the 10 Canadian provinces, with the hope of offering advice to policy makers on where current policy can be improved or new policies implemented. The results summarized in Figure 1 and Table 2 provide a clear picture of where each province stands with regards to the implementation of effective policies and programs for reducing alcohol-related harm, both in relation to other provinces and to the ideal.

These findings represent a useful planning resource to improve the effectiveness of efforts intended to mitigate harm to individuals, families, and communities and to reduce alcohol-related costs. With regard to dimension nine, undertaking a comprehensive planning process for a provincial alcohol strategy is a recommended approach to raise the profile of alcohol issues and stimulate a coordinated evidence-based response. Provinces can begin the process by reviewing their standing in each dimension and setting target scores with the aim of achieving ideal scores on a number of the 10 dimensions. A fully developed provincial strategy would also detail the means by which targeted scores would be realized.

In general, progress within any dimension is achieved through a combination of policy initiatives, including legislation, regulations, operations, and program initiative, which will extend across various ministries and involve a broad range of delivery agents. All such activity must be driven by the recognition that alcohol-related harm places a substantial and unacceptable burden on Canadian society and that a considerable proportion of that burden is preventable. 
The project team has engaged in a number of knowledgeexchange activities to help inform further development of alcohol policies across Canada. Communications with various liquor boards and agencies, ministries of finance and health, including the Council of Chief Medical Officers of Health, and non-government organizations dealing with public health issues related to alcohol use have taken place at all stages of the project. The policy implications of the findings of the project were communicated in an in-depth report (Giesbrecht et al., 2013), as well as in several province-specific summary reports that have been widely disseminated to several key stakeholders and government departments dealing with alcohol issues. The project team has also participated in a number of consultations with governments and stakeholders alike to strengthen alcohol policies across several regions in Canada.

Following the release of the main report (Giesbrecht et al., 2013), 10 province-specific reports have been released that included focused analyses, updates on recent alcohol policy developments, and recommendations focusing on the provincial context. They have been widely disseminated and have generated media attention. The findings from this project have provided stakeholders-including public health units, non-government organizations, and several government ministries - with a snapshot of alcohol policies across the provinces. This information has been incorporated into several monitoring activities by these organizations.

The findings of this project have been used to inform alcohol policy reviews in at least five provinces, and in two provinces there is progress on a provincial alcohol strategy. Québec, Alberta, and Nova Scotia have strengthened drinking and driving policies, while British Columbia recently announced a number of promising recommendations to improve their alcohol policies, one of which was to strengthen their pricing system. Nova Scotia has strengthened harm reduction policies regarding alcohol sponsorship and is exploring options for conveying risks associated with alcohol use. Cancer Care Ontario is using our protocol in developing a tracking and monitoring system on access to alcohol at the regional level in Ontario.

\section{Acknowledgements}

This paper is based in part on a presentation at the $40^{\text {th }}$ Alcohol Epidemiology Symposium of the Kettil Bruun Society, Torino, Italy, June 9-13, 2014, and on Giesbrecht et al. (2013). We gratefully acknowledge receipt of data from the Provincial Liquor Boards as well as from the Provincial Ministries of Finance, Provincial Ministries of Health, and ministries responsible for the control and sale of alcohol in each province. The information they provided was critical to the analyses employed. We thank MADD Canada for permission to use materials collected for their 2012 Provincial and Territorial Review. We received feedback on the selection of policy dimensions and scoring template from Thomas Greenfield, Esa Österberg, and Robin Room. We acknowledge Francois Benoit, Denise De Pape, Ann Dowsett Johnston, and Robert Strang for their contributions to this project, as well as comments provided by Thomas Babor. The views and opinions expressed in this paper are those of the authors and do not necessarily reflect the perspectives or policies of the persons and organizations acknowledged.

\section{References}

Anderson, P., Chisholm, D., \& Fuhr, D. (2009). Alcohol and Global Health 2: Effectiveness and costeffectiveness of policies and programmes to reduce the harm caused by alcohol. Lancet, 373, 2234-2246.

Babor, T. F., Caetano, R., Casswell, S., Edwards, G., Giesbrecht, N., Graham, K., . . . Rossow, I. (2010). Alcohol: No ordinary commodity - Research and public policy. Oxford, England: Oxford University Press.

Brand, D. A., Saisana, M., Ryan, L. A., Pennoni, F., \& Lowenfels, A. B. (2007). Comparative analysis of alcohol control policies in 30 countries. PLOS Medicine, 151(4), 0752-0759.

British Medical Association Board of Science. (2009). Under the influence: The damaging effect of alcohol marketing on young people. Retrieved from http://www.alcohollearningcentre.org.uk/_library/unde rtheinfluence_tcm41-1900621.pdf

Butt, P., Beirness, D., Gliksman, L., Paradis, C., \& Stockwell, T. (2011). Alcohol and health in Canada: A summary of evidence and guidelines for low risk drinking. Retrieved from http://www.ccsa.ca/ 2011\%20CCSA\%20Documents/2011-Summary-ofEvidence-and-Guidelines-for-Low-Risk\%20Drinkingen.pdf

Canadian Public Health Association. (2011). Too high a cost: A public health approach to alcohol policy in Canada. Retrieved from http://www.cpha.ca/uploads/ positions/position-paper-alcohol_e.pdf

Carragher, N., Byrnes, J., Doran, C. M., \& Shakeshaft, A. (2014). Developing an alcohol policy assessment toolkit: Application in the western Pacific. Bulletin of the World Health Organization, 92, 726-733. Retrieved from: http://www.who.int/bulletin/volumes/ 92/10/13-130708/en/

Chisholm, D., Rehm, J., Van Ommeren, M., \& Monteiro, M. (2004). Reducing the global burden of hazardous alcohol use: A comparative cost-effectiveness analysis. Journal of Studies on Alcohol and Drugs, 65(6), 782-793.

Elder, R. W., Voas, R., \& Beirness, D. (2011). Effectiveness of ignition interlocks for prevention alcohol-impaired driving and alcohol-related crashes: A community guide systematic review. American Journal of Preventive Medicine, 40, 362-376.

Giesbrecht, N. (2007). Reducing alcohol-related damage in populations: Rethinking the roles of education and persuasion interventions. Addiction, 102, 1345-1349.

Giesbrecht, N., Cukier, S., \& Steeves, D. (2010). Collateral damage from alcohol: Implications of second-hand effects of drinking for populations and health priorities. Addiction, 105, 1323-1325. 
Giesbrecht, N., Stockwell, T., Kendall, P., Strang, R., \& Thomas, G. (2011). Alcohol: Reducing the toll through focused interventions and public health policies. CMAJ, 183 (4), 450-455.

Giesbrecht, N., Wettlaufer, A. April, N., Asbridge, M., Cukier, S., Mann, R., . . . Vallance, K. (2013). Strategies to reduce alcohol-related harms and costs in Canada: A comparison of provincial policies. Toronto, Canada: Centre for Addiction and Mental Health.

Gordon, R., Harris, F., Marie-Mackintosh, A., \& Moodie, C. (2011). Assessing the cumulative impact of alcohol marketing on young people's drinking: Cross-sectional data findings. Addiction Research and Theory, 19(1), 66-75.

Greenfield, T. K., \& Kaskutas, L. A. (1998). Five years exposure to alcohol warning label messages and their impacts: Evidence from diffusion analysis. Applied Behavioral Science Review, 6(1), 30-68.

Hahn, R. A., Middleton, J. C., Elder, R., Fielding, J., Naimi, T. S., . . . Campbell, C. A. (2012). Effects of alcohol retail privatization on excessive alcohol consumption and related harms: A community guide systematic review. American Journal of Preventative Medicine, 42(4), 418-427.

Health Canada. (2007). Best practices: Treatment and rehabilitation of Driving While Impaired offenders. Retrieved from http://www.hc-sc.gc.ca/hc-ps/ alt_formats/hecs-sesc/pdf/pubs/adp-apd/bp_treatmentmp_traitement/treatment_rehab_driving_impaired_pra ctices.pdf

Kaner, E. F. S., Dickinson, H. O., Beyer, F. R., Pienaar, E., Schlesinger, C., Campbell, F., . . . Heather, N. (2009). The effectiveness of brief alcohol interventions in primary care settings: A systematic review. Drug and Alcohol Review, 28, 301-323.

Karlsson, T., \& Österberg, E. (2001). A scale of formal alcohol control policy in 15 European countries. Nordisk Alkohol \& Narkotikatidskrift, 18(English Suppl.), 117-131.

Kellner, F. (2005). Alcohol-related problems: Prevalence, incidence and distribution. In E. Adlaf, P. Begin, \& A. Sawka (Eds.), Canadian Addiction Survey: A national survey of Canadians' use of alcohol and other drugs: Prevalence of use and related harms: Detailed report (pp. 33-47). Ottawa, Canada: Canadian Centre on Substance Abuse.

Koordeman, R., Anschutz, D. J., \& Engels, R. (2012). Alcohol portrayals in movies, music videos and soap operas and alcohol use of young people: Current status and future challenges. Alcohol and Alcoholism, 47(5), 612-623.

Lim, S., Vos, T., Flaxman, A., Danaei, G., Shibuya, K., Adair-Rohani, H., . . . Memish, Z. A. (2012). A comparative risk assessment of burden of disease and injury attributable to 67 risk factors and risk factor clusters in 21 regions, 1990-2010: A systematic analysis for the Global Burden of Disease Study 2010. Lancet, 380, 2224-2260.

Lin, E., \& Durbin, J. (2008). Adapting the balanced scorecard for mental health and addictions: An inpatient example. Health Policy, 3(4), 160-174.
Lipperman-Kreda, S., Grube, J. W., \& Paschall, M. J. (2010). Community norms, enforcement of minimum legal drinking age laws, personal beliefs and underage drinking: An explanatory model. Journal of Community Health, 35, 249-257.

Livingston, M. (2012, April). Implications of outlet density, type and concentration on alcohol consumption \& harm. Seminar presentation, Centre for Addiction and Mental Health, Toronto, Canada.

Macdonald, S., Wells, S., \& Giesbrecht, N. (1999). Unrecorded alcohol consumption in Ontario, Canada: Estimation procedures and research implications. Drug and Alcohol Review, 18(1), 21-29.

Mann, R. E. (2002). Choosing a rationale threshold for the definition of drunk driving: What research recommends. Addiction, 97, 1237-1238.

Murie, A. (2013) Personal communication to N. Giesbrecht, January 13, 2013.

Naimi, T. S., Blanchette, J., Nelson, T. F., Nguyen, T., Oussayef, N., Heeren, T. C, . . . Xuan, Z. (2014). A new scale of the U.S. alcohol policy environment and its relationship to binge drinking. American Journal of Preventive Medicine, 46(1), 10-16.

National Alcohol Strategy. (2007). Reducing alcoholrelated harm in Canada: Toward a culture of moderation. Recommendations for a national alcohol strategy. Alberta Alcohol and Drug Abuse Commission, Canadian Centre on Substance Abuse, \& Health Canada.

Nelson, T. F., Xuan, Z., Babor, T., Brewer, R. D., Chaloupka, F. J., Gruenewald, P., . . . Naimi, T. S. (2013). Efficacy and strength-of-evidence of U.S. alcohol control policies. American Journal of Preventive Medicine, 45(1), 19-28.

Paglia-Boak, A., Adlaf, E. M., \& Mann, R. E. (2011). Drug use among Ontario students 1977-2011: Detailed OSDUHS findings (CAMH Research Document Series No. 32). Toronto, Canada: Centre for Addiction and Mental Health.

Patra, J., Taylor, B., Rehm, J., Baliunas, D., \& Popova, S. (2007). Substance-attributable morbidity and mortality changes to Canada's epidemiological profile: Measurable differences over a ten-year period. Canadian Journal of Public Health, 98(3), 228-234.

Peck, R., Arstein-Kerslake, G. W., \& Helander, C. J. (1994). Psychometric and biographical correlates of drunk-driving recidivism and treatment program compliance. Journal of Studies on Alcohol, 55, 667678.

Popova, S., Giesbrecht, N., Bekmuradov, D., \& Patra, J. (2009). Hours and days of sale and density of alcohol outlets: Impacts of alcohol consumption and damage: A systematic review. Alcohol and Alcoholism, 44(5), 500-516.

Rehm, J., Baliunas, D., Brochu, S., Fischer, B., Gnam, W., Patra, J., . . . Taylor, B. (2006). The costs of substance abuse in Canada 2002. Ottawa, Canada: Canadian Centre on Substance Abuse.

Solomon, R., Cardy, J., Noble, I., \& Wulkan, R. (2012). Mapping our progress to safer roads: The 2012 provincial and territorial legislative review. Retrieved from http://www.madd.ca/media/docs/MADD_ 
Canada_2012_Provincial_and_Territorial_Legislative _Review_FINAL.pdf

Statistics Canada. (2011a). Canadian Community Health Survey 2009/2010, custom table: Monthly and weekly risky drinking (five or more drinks on occasion), age 15 and over, by sex and province, Canada excluding the Territories.

Statistics Canada. (2011b). Canadian Community Health Survey 2009/2010, custom table: Frequency of having five or more drinks, age 15 and over, by sex and province (excluding Territories).

Statistics Canada. (2011c). Table 183-0019 - Volume of sales of alcoholic beverages in litres of absolute alcohol and per capita 15 years and over, fiscal years ended March 31, annual (litres).

Stockwell, T, \& Chikritzhs, T. (2009). Do relaxing trading hours for bars and clubs mean more relaxed drinking? A review of international research on the impacts of changes to permitted hours of drinking. Crime Prevention and Community Safety, 11, 153-170.

Stockwell, T., Zhao, J., \& Thomas, G. (2009). Should alcohol policies aim to reduce total alcohol consumption? New analyses of Canadian drinking patterns. Addiction Research and Theory, 17(2), 135151.

Stockwell, T., Zhao, J., Giesbrecht, N., Macdonald, S., Thomas, G. \& Wettlaufer A. (2012). The raising of minimum alcohol prices in Saskatchewan, Canada: Impacts on consumption and implications for public health American Journal of Public Health, 102: e103e110. doi:10.2105/AJPH.2012.301034

Strategy for Patient-Oriented Research (2011) Retrieved from: http://www.cihr-irsc.gc.ca/e/documents/PO_Research_Strategy-eng.pdf

Thomas, G. (2012). Alcohol Price Policy Series: Report 3. Price policies to reduce alcohol-related harm in Canada. Ottawa, Canada: Canadian Centre on Substance Abuse.

van Hoof, J. J., de Jong, M. D. T., Fennis, B. M., \& Gosselt, J. F. (2009). There's alcohol in my soap: Portrayal and effects of alcohol use in a popular television series. Health Education Research, 24(3), 421-429.

Wagenaar, A. C., Tobler, A., \& Komro, K. (2010). Effects of alcohol tax and price policies on morbidity and mortality: A systematic review. American Journal of Public Health, 100, 2270-2278.

Wagenaar, A. C., \& Toomey, T. L. (2002). Effects of minimum drinking age laws. Review and analysis of the literature from 1960-2000. Journal of Studies on Alcohol, 63, 206-225.

World Health Organization. (1986). Ottawa charter for health promotion. An international conference on health promotion, November 17-21. Ottawa, Canada: Author.

World Health Organization. (2010). Global strategy to reduce the harmful use of alcohol. Geneva, Switzerland: Author.

\section{Appendix A}

\section{Policy Dimensions and Respective Indicators}

The following is a detailed summary of the 10 policy dimensions and their respective indicators used in the current project.

\section{Pricing}

Although there are important differences, alcohol is like many other products in that demand is inversely related to its price. This means that when the price of alcohol products increase, sales decrease if other factors such as income are kept constant. Several decades of international research show that increasing the price of alcohol is one of the most effective approaches for reducing consumption and, importantly, alcohol-related harm at the population level (Babor et al., 2010; Wagenaar, Tobler, \& Komro, 2010; Stockwell et al., 2012). Associated policy measures assessed in the scoring rubric, which primarily target heavy drinkers and risky products, include the following:

- Minimum prices: Establishing the lowest cost at which alcohol can be purchased, standardized in relation to the alcohol content and container size.

- Indexing prices to inflation: Aligning alcohol pricing with the Consumer Price Index.

- $\quad$ Pricing on alcohol content: Equalizing prices for non-standard products based on alcohol strength (i.e., for beverages of the same volume, stronger alcohol content is priced higher).

\section{Alcohol Control Systems}

Direct government involvement in the retail sale of alcohol has been shown to reduce risky drinking practices. Conversely, private involvement in retail sales, including private retail stores, has been linked to substantial increases in per capita alcohol sales, consumption, and related harm (Babor et al., 2010; Hahn et al., 2012). In addition, ferment-on-premises outlets and ferment-at-home kits increase the availability of inexpensive alcohol and attract high-risk drinkers (Macdonald, Wells, \& Giesbrecht, 1999). Government retail sales monopolies can encourage public awareness of alcohol-related risk through counteradvertising strategies and social marketing programs. More significantly, they play an important supportive role in a comprehensive alcohol policy strategy through control of outlet density, hours of operation, and challenge and refusal programs (Anderson et al., 2009; Babor et al., 2010). Indicators used for the dimension of Alcohol Control Systems included the following: 
- Type of retail system: The proportion of government-run outlets to private outlets for the retail sale of alcohol (including agency stores and ferment-on-premises options), with higher scores assigned to government-run systems.

- Alcohol sales beyond on- and off-premises retail outlets: The extent to which restrictions or prohibitions are placed on alcohol sales through delivery services, online shopping, ferment-on-premises outlets, and ferment-at-home kits.

- Emphasis on social responsibility: The proportion of per capita spending dedicated to advertising alcohol versus social responsibility initiatives.

- Ministry responsible for oversight: Assessing the ministry to which each jurisdiction reports with respect to the sale and control of alcohol and the extent to which it includes a public health and safety perspective that recognizes alcohol as a potential health risk.

\section{Physical Availability}

The physical availability of alcohol is reflected in the number of outlets, licensed establishments, and points of sale as a density rate by the population of the province and the hours and days of operation. Increases in availability have been shown to be associated with increases in weekly and per-occasion consumption, as well as drinking in high-risk contexts (e.g., before driving) (Babor et al., 2010; Livingston, 2012; Popova, Giesbrecht, Bekmuradov, \& Patra, 2009; Stockwell \& Chikritzhs, 2009). The following indicators for the dimension of Physical Availability were used:

- Regulations for outlet density: The extent to which outlet density is fixed in relation to the population base, whether there are regulations that provide the authority to determine the location or number of outlets in a given area to avoid a concentration of outlets (e.g., entertainment districts), and whether regulations allow for citizen input on new licenses and outlets.

- Actual density: The measured number of on- and off-premises outlets per 10,000 persons aged 15 and over.

- Hours of operation: Measured against the standard of nine hours per day for off-premises outlets, with no earlymorning or late-night sales, and of 14 hours per day for on-premises outlets between 11:00 a.m. and 1:00 a.m., with no early-morning or late-night sales.

\section{Drinking and Driving}

Impaired driving is a leading cause of alcohol-related death and injury worldwide (Lim et al., 2012). Significant impairment and increased collision risk are evident at a blood alcohol concentration (BAC) of .05\% or higher. Establishing a legal per se limit at or below this level diminishes the likelihood of collisions, injuries, and fatalities (Mann, 2002). The risk of collision is considerably increased for young and new drivers. Graduated License Programs (GLP) which reduce BAC thresholds or prohibit alcohol in the bloodstream are effective responses (Paglia-Boak, Adlaf, \& Mann, 2011). Drivers with previous impaired driving offenses present a substantially greater risk for recidivism, collision, and alcohol-related harm (Peck, Arstein-Kerslake, \& Helander, 1994). These risks can be reduced through remedial programs, either alone or combined with significant sanctions, such as vehicle impoundment or interlock programs (Elder, Voas, \& Beirness, 2011; Health Canada, 2007). Several indicators for the dimension of Drinking and Driving were used:

- Licensing: The adoption of a comprehensive, three-year GLP with police enforcement powers for young or new drivers, with .00\% BAC limits for drivers under 21 years of age and with fewer than five years driving experience.

- Licensing suspension and revocations: The implementation of significant sanctions to effectively deter impaired driving and repeat offenses. Exceeding a BAC of.05\% should be met with a minimum seven-day recorded license suspension and \$150-\$300 reinstatement fee, as well as vehicle impoundment and remedial program participation.

- Vehicle and remedial programs: The extent to which federal (i.e., Criminal Code) impaired driving offenders are subject to comprehensive sanctions, including both restrictive components (e.g., ignition interlocks and vehicle forfeiture) and rehabilitative components (e.g., remedial programs). Repeat offenders should face augmented license suspensions, vehicle impoundment, or forfeiture and extended ignition interlock penalties.

\section{Marketing and Advertising}

Alcohol marketing and advertising is associated with enhanced perceptions of the benefits of drinking and minimized perceptions of potential harm (British Medical Association Board of Science, 2009; van Hoof, de Jong, Fennis, \& Gosselt, 2009). These effects are particularly powerful among youth and young adults, where greater exposure to marketing and advertising is linked in diverse contexts to increased alcohol consumption and earlier initiation to alcohol use (Koordeman, Anschutz, \& Engels, 2012; Gordon, Harris, Marie-Mackintosh, \& Moodie, 2011). Indicators for the dimension of Marketing and Advertising used in this project include the following:

- Comprehensiveness of regulations: The extent to which restrictions on alcohol marketing extend beyond federal guidelines in relation to content and whether they included restrictions on placement, number, and the promotion of price.

- Enforcement of regulations: The presence of specific authority to ensure compliance with regulations for alcohol marketing and advertising. Violations should be addressed by a formal complaint system and met with strict and substantial penalties. 
- Focus of the liquor board's website: The extent to which the provincial liquor boards' website home pages place emphasis on social responsibility initiatives compared to product promotion.

- $\quad$ Sponsorship: The extent to which policies restrict the public display of alcohol manufacturer names and logos.

\section{Legal Drinking Age}

A minimum age of 21 for the legal purchase and consumption of alcohol significantly decreases alcohol-related problems among youth and young adults, as demonstrated in the United States (Babor et al., 2010). This strategy is most beneficial when implemented consistently across jurisdictions (Wagenaar \& Toomey, 2002). Further, perceptions among those under 21 that enforcement is strict and that the community stands against underage drinking tend to depress the extent of their drinking (Lipperman, Grube, \& Paschall, 2010). Indicators for the dimension of Legal Drinking Age used in this project include the following:

- Level of legal drinking age and supporting legislation: The minimum legal drinking age of the province and the passage of legislation prohibiting the purchase of alcohol by and sale or service of alcohol to individuals below the minimum legal drinking age, with 21 years being the ideal.

- Enforcement of the legal drinking age in on- and off-premises outlets: The implementation of law enforcement initiatives in support of legal drinking age regulation (including mystery shopper and liquor inspection programs).

\section{Screening, Brief Intervention, and Referral}

The availability of screening, brief intervention, and referral (SBIR) initiatives are remarkably effective for those exhibiting early-stage alcohol dependence (Kaner et al., 2009). The integration of SBIR into primary and secondary health care settings has demonstrated considerable public health benefit, including a $22 \%$ net reduction in consumption among hazardous drinkers (Chisholm, Rehm, Van Ommeren, \& Monteiro, 2004) and subsequent reductions in health care utilization and costs. Indicators for Screening, Brief Intervention, and Referral include the following:

- The inclusion of SBIR in a provincial strategy or action plan: The adoption of a provincial plan for SBIR that targets at-risk groups and especially the general population.

- Practice guidelines and/or position paper: SBIR identified as normal or best practice in a position or guideline paper authored by credible provincial associations.

- Fee for service codes: The extent to which physicians receive reimbursement from the provincial government for services related to SBIR.

\section{Server and Management Training, Challenge, and Refusal Programs}

Mandatory training for servers and management in licensed premises, along with challenge and refusal programs for off-premises sales, improve compliance with alcohol legislation and regulations. Rigorous implementation of these programs has a positive effect on the incidence of intoxication and impaired driving among patrons of licensed premises and on service to those under the minimum legal drinking age (Babor et al., 2010). Impact for on-premises programs is greatest when intensive training is provided and is supplemented by strict enforcement of related liquor laws and regulations (Stockwell, 2006). Similarly, the impact of challenge and refusal programs is expected to be greater when acknowledged by provincial alcohol management authorities and supplemented with mandatory documentation and ongoing evaluation.

Indicators for Server and Management Training (on-premises) include the following:

- Server and management training program policy status: The existence of legislation or regulation requiring mandatory training programs, including refusal of service to intoxicated patrons, for all management and staff of licensed events and venues.

- Quality of the server and management training program: The extent to which venues employ a comprehensive, upto-date, and evidence-based server intervention program.

- Program enforcement: The extent to which the effectiveness of intervention programs is monitored.

Indicators for Challenge and Refusal Programs (off-premises) include the following:

- Challenge and refusal program policy status: The existence of challenge and refusal programs, including refusal of service to underage and intoxicated people.

- Quality of the challenge and refusal program: The extent to which outlets employ comprehensive, up-to-date, and evidence-based challenge criteria and training practices.

- Program enforcement: The extent to which the effectiveness of challenge and refusal programs are monitored and enforced. 


\section{Provincial Alcohol Strategy}

Provincial Alcohol Strategies are comprehensive and systematic approaches to the prevention and remediation of alcohol problems embodied in legislation, regulations, and government policy documents. For greatest impact, key elements of the WHO Global Strategy to Reduce the Harmful use of Alcohol (2010), including leadership, health service responses, community action, pricing and marketing policies, and monitoring and evaluation activities, should be considered (Babor et al., 2010). Several indicators for the dimension of Provincial Alcohol Strategies were used:

- Main focus of the provincial strategy: The extent to which the scope of the strategy focuses on alcohol-specific issues.

- Range of policy interventions: The extent to which the provincial strategy incorporates the priority population-level interventions articulated by the WHO Global Strategy to Reduce the Harmful use of Alcohol.

\section{Warning Labels and Signs}

Warning labels on alcohol containers and at point-of-sale locations represent unique opportunities to communicate information about alcohol-related harms to a large proportion of the drinker population (Greenfield \& Kaskutas, 1998). While the effectiveness of warning labels is limited as an isolated strategy, the information transmitted provides a knowledge base upon which other prevention measures can build (Babor et al., 2010; Giesbrecht, 2007). Indicators for the dimension of Warning Labels and Signs were as follows:

- The provincial policy on warning labels: The requirement for warning labels to be placed on alcohol containers.

- The quality of the warning label messages: The extent to which labels are prominent, provide a variety of concrete warnings, and are supported by graphics.

- The provincial policy on warning signs: The requirement for point-of-sale warning signs in on- and off-premises locations.

- The quality of warning sign messages: The extent to which warning signs provide clear, concrete information that addresses a range of health and safety topics and are supported by graphics. 